\title{
Endovascular Treatment of Unruptured Paraclinoid Aneurysms: Single-Center Experience with 400 Cases and Literature Review
}

\author{
(D). Shimizu, (DH. Imamura, (D). Mineharu, DH. Adachi, (D). Sakai, and DN. Sakai
}

\begin{abstract}
BACKGROUND AND PURPOSE: Paraclinoid aneurysms have been increasingly treated endovascularly. The natural history of these aneurysms has gradually been elucidated. The purpose of this study was to assess the safety and efficacy of endovascular treatment for these aneurysms.
\end{abstract}

MATERIALS AND METHODS: We performed a retrospective review of 377 patients with 400 paraclinoid aneurysms treated between January 2006 and December 2012. Their clinical records, endovascular reports, and radiologic and clinical outcomes were analyzed. Because aneurysms $\geq 7 \mathrm{~mm}$ are at higher risk of rupture, we classified aneurysms as small $(<7 \mathrm{~mm}$ ) or large ( $\geq 7 \mathrm{~mm})$.

RESULTS: Overall, 115 of the 400 aneurysms (28.8\%) were large ( $\geq 7 \mathrm{~mm})$. Thromboembolic complications were found significantly more often with large aneurysms than with small ones $(7.4 \% \mathrm{vs} 1.0 \%, P=.001)$. Hemorrhagic complications were found only with small aneurysms $(0.7 \%)$. The 6-month morbidity rates were similar for small $(1.0 \%)$ and large $(0.8 \%)$ aneurysms. Immediate angiographic outcomes were similar $(P=.37)$, whereas recurrences and retreatment occurred more frequently with large aneurysms $(P=.001$ and $P=.007$, respectively). Multivariate analysis showed that aneurysm size was the only independent predictor for recurrence $(P=.005)$. Most recurrences (81\%) were detected by scheduled angiography at 6 months.

CONCLUSIONS: Aneurysm size influenced the type of complication (thromboembolic or hemorrhagic) and the recurrence rate. Given the approximately $1 \%$ annual rupture rate for aneurysms $\geq 7 \mathrm{~mm}$, analysis of our data supports the rationale of using prophylactic endovascular treatment for unruptured paraclinoid aneurysms $\geq 7 \mathrm{~mm}$.

ABBREVIATION: UCAS = Unruptured Cerebral Aneurysm Study

$\mathbf{P}$ araclinoid aneurysms are located in the clinoid and ophthalmic segments of the ICA. ${ }^{1}$ Because of the anatomic structures adjacent to the segments of the ICA (eg, anterior clinoid process, cavernous sinus, optic apparatus), microsurgical treatment of a paraclinoid aneurysm can be challenging. ${ }^{2}$ With the development of novel devices and the need for lessinvasive treatment, an increasing number of paraclinoid aneurysms have been treated by endovascular treatment. The natural history of unruptured intracranial aneurysms has been

Received June 4, 2015; accepted after revision August 21.

From the Department of Neurosurgery (K.S., H.I., H.A., N.S.), Kobe City Medical Center General Hospital, Kobe, Japan; Division of Neuroendovascular Therapy (C.S., N.S.), Institute of Biomedical Research and Innovation, Kobe, Japan; and Department of Neurosurgery (Y.M.), Kyoto University Graduate School of Medicine, Kyoto, Japan.

Please address correspondence to Kampei Shimizu, MD, Department of Neurosurgery, Kobe City Medical Center General Hospital, 2-1-1 Minatojima-Minamimachi, Chuo-ku, Kobe 650-0047, Japan; e-mail: k.shimizu.830923@gmail.com

- Indicates open access to non-subscribers at www.ajnr.org

http://dx.doi.org/10.3174/ajnr.A4577 reported as represented by the International Study of Unruptured Intracranial Aneurysms and the Unruptured Cerebral Aneurysm Study (UCAS) by Japanese investigators. ${ }^{3-8}$ According to these studies, the size and location of the aneurysms were regarded as leading predictors of rupture. The UCAS Japan investigators reported that the annual rupture rate of paraclinoid aneurysms was $1 \%$ overall when they were $7-24 \mathrm{~mm}$ in largest dimension. ${ }^{7}$ Therefore, aneurysms $\geq 7 \mathrm{~mm}$ would be good candidates for prophylactic endovascular treatment. There have been no studies reported, however, that analyzed the complication and recurrence rates relative to the annual rupture rate. ${ }^{9-15}$

The purpose of the present study was to assess the safety and efficacy of endovascular treatment for paraclinoid aneurysms in a cohort of 400 cases. The advantage of this study was that we could estimate the clinical outcome of endovascular treatment for these aneurysms in comparison with the natural history of an aneurysm of the same size in the same ethnic population by using the UCAS Japan data. 


\section{MATERIALS AND METHODS Study Population}

Between January 2006 and December 2012, a total of 889 endovascular coil embolizations were conducted for unruptured intracranial aneurysms at Kobe City Medical Center General Hospital. Among these procedures, 415 were applied to 403 paraclinoid aneurysms in 380 patients. Surgical clipping was chosen for only 6 paraclinoid aneurysms during this period. Three aneurysms in 3 patients were excluded because they were treated by parent artery occlusion. Thus, a total of 400 paraclinoid aneurysms in 377 patients were included in the study.

Paraclinoid aneurysms at our institution are categorized as anterior wall, ventral paraclinoid, true ophthalmic, or carotid cave aneurysms according to the al-Rodhan et al ${ }^{16}$ classification modified by Iihara et al. ${ }^{17}$ Aneurysm size was categorized as small $(<7 \mathrm{~mm})$ or large $(\geq 7 \mathrm{~mm})$. We retrospectively reviewed the medical records and radiologic data for these patients. Informed consent for the treatment was obtained from all the patients, and our institutional review board approved the protocol.

The patient characteristics used in this analysis included age, sex, medical history (hypertension, diabetes mellitus, dyslipidemia, polycystic kidney, number of aneurysms, smoking habit, family history of SAH), and neurologic symptoms. Radiologic characteristics included dome and neck size, dome:neck ratio, and location of aneurysms.

\section{Endovascular Procedures}

Procedures were performed with the patient under local anesthesia. All the patients were pretreated with daily doses of $100 \mathrm{mg}$ of aspirin and $75 \mathrm{mg}$ of clopidogrel for $>5$ days in preparation for a stent-assisted technique. After femoral puncture, a bolus of $4000-$ $5000 \mathrm{U}$ of heparin was administered intravenously, followed by intermittent intravenous infusion of 1000-2000 $\mathrm{U}$ of heparin to maintain the activated clotting time at 2 times the patient's baseline throughout the procedure. After the procedure, the patients were administered continuous intravenous argatroban $60 \mathrm{mg} /$ day for 48 hours. Patients who underwent a stent-assisted procedure continued treatment with the dual antiplatelet therapy described above for 6 months, followed by $100 \mathrm{mg}$ of aspirin or $75 \mathrm{mg}$ of clopidogrel per day indefinitely. Otherwise, patients were treated with $100 \mathrm{mg}$ of aspirin or $75 \mathrm{mg}$ of clopidogrel per day for 6 months, followed by no antiplatelet therapy.

The decision about whether a stent-assisted technique should be used was based on the risk of coil protrusion into the parent artery. We started measuring aspirin-reaction units and P2Y12 reaction units in 2010 and used these values for the decisionmaking process in 2013. Therefore, the antiplatelet function test was not taken into account for the selection of antiplatelet drugs during the study period.

\section{Angiographic Outcomes and Follow-Up}

Angiographic outcomes were divided into 3 categories: complete occlusion, neck remnant, body filling. ${ }^{18}$ Immediate angiographic outcomes were assessed by using DSA on the date of treatment. Follow-up angiographic outcomes were assessed by DSA and/or MRA. Recurrence was defined as any decrease in the occluded area demonstrated by DSA or MRA. Recurrences were subdivided into those that required intervention and those that were treated conservatively. For each aneurysm, angiographic follow-up by DSA was scheduled for 6 months after treatment. Radiographic follow-up by MRA was performed at various intervals. When recanalization was suspected, DSA was performed to identify indications for additional treatment.

Complications related to the procedures were recorded based on symptoms and radiologic examination. Ischemic and hemorrhagic complications were diagnosed by using CT and MRI. When patients displayed neurologic symptoms, including headache, radiologic examinations were conducted just after treatment. Otherwise, those examinations were routinely conducted on the day after treatment. Other complications, such as visual impairment and oculomotor nerve palsy, were considered to be procedure-related based on the time of onset and radiographic analysis. Good clinical outcome was defined as an mRS of $0-2$ at 6 months. Complications that left a neurologic deficit at 6 months were described as permanent morbidity.

In this study, aneurysm size was classified as small $(<7 \mathrm{~mm})$ or large ( $\geq 7 \mathrm{~mm}$ ). We compared the results according to the aspects of the aneurysm location, therapeutic strategy (adjunctive technique), angiographic outcome, recurrence rate, frequency of complications, and subsequent clinical outcomes.

\section{Statistical Analysis}

The $\chi^{2}$ test, Fisher exact test, and Student $t$ test were used as appropriate. Factors found to be predictive for recurrence in the univariate analysis $(P<.15)$ were entered into a multivariate logistic regression analysis. A value of $P<.05$ was considered to indicate statistical significance. All statistical analyses were performed with JMP software, version 10.0 (SAS Institute, Cary, North Carolina).

\section{RESULTS}

\section{Demographics}

A total of 400 unruptured paraclinoid aneurysms in 377 patients were treated endovascularly. Characteristics of the patients and aneurysms are summarized in Table 1 . Two hundred eighty-five aneurysms $(71.3 \%)$ were small, and $350(87.5 \%)$ occurred in female patients. The mean age of the patients was $56.2 \pm 11.2$ years (range, $27-80$ years), and 23 patients $(6.1 \%)$ were $\geq 70$ years. The numbers of patients who had a medical history of hypertension, diabetes mellitus, dyslipidemia, or polycystic kidney disease were 151 (40.1\%), 19 (5.0\%), 83 (22.0\%), and 0, respectively. Seventyeight patients $(20.7 \%)$ were former or current smokers, 45 (11.9\%) had a family history of SAH, and $86(22.6 \%)$ had multiple aneurysms. Three hundred eighty-three aneurysms (95.8\%) were asymptomatic. Variables that were seen significantly more often or were more frequently observed in patients with large aneurysms included older age $(P=.003)$, former or current smoking habit $(P=.042)$, and symptoms caused by the aneurysm $(P=$ $.002)$.

Radiologic characteristics of the aneurysms are summarized in Table 2. The mean dome:neck ratio was significantly lower with small aneurysms $(1.6 \pm 0.4)$ than with large aneurysms $(2.2 \pm$ $0.7)(P<.001)$. The location of aneurysms was also significantly different between the groups $(P=.003)$. The most prevalent lo- 
Table 1: Characteristics of patients and aneurysms ${ }^{\mathrm{a}}$

\begin{tabular}{|c|c|c|c|c|c|}
\hline \multirow[b]{2}{*}{ Characteristic } & \multirow[b]{2}{*}{ Patients } & \multicolumn{4}{|c|}{ Aneurysms } \\
\hline & & Total & $<7 \mathrm{~mm}$ & $\geq 7 \mathrm{~mm}$ & $P$ \\
\hline $\begin{array}{l}\text { Total no. } \\
\text { Age }\end{array}$ & 377 & 400 & 285 & 115 & \\
\hline Mean, y & $56.2 \pm 11.2$ & $56.8 \pm 11.1$ & $55.7 \pm 11.1$ & $59.3 \pm 10.6$ & .003 \\
\hline$\geq 70 y$ & $23(6.1 \%)$ & $23(5.8 \%)$ & $17(6.0 \%)$ & $6(5.2 \%)$ & .209 \\
\hline Female sex & $330(87.5 \%)$ & $350(87.5 \%)$ & $250(87.7 \%)$ & $100(87.0 \%)$ & .835 \\
\hline Medical history & & & & & \\
\hline Hypertension & $151(40.1 \%)$ & $162(40.5 \%)$ & $108(37.9 \%)$ & $54(47.0 \%)$ & .095 \\
\hline Diabetes mellitus & $19(5.0 \%)$ & $20(5.0 \%)$ & $14(4.9 \%)$ & $6(5.2 \%)$ & .899 \\
\hline Dyslipidemia & $83(22.0 \%)$ & $86(21.5 \%)$ & $63(22.1 \%)$ & $23(20.0 \%)$ & .643 \\
\hline Polycystic kidney & $0(0 \%)$ & $0(0 \%)$ & $0(0 \%)$ & $0(0 \%)$ & 1 \\
\hline Multiple aneurysms & $86(22.6 \%)$ & $108(27.0 \%)$ & $81(28.4 \%)$ & $27(23.5 \%)$ & .314 \\
\hline$\geq 3$ Aneurysms & $11(2.9 \%)$ & $18(4.5 \%)$ & $12(4.2 \%)$ & $6(5.2 \%)$ & .660 \\
\hline Former or current smoking & $78(20.7 \%)$ & $82(20.5 \%)$ & $51(17.9 \%)$ & $31(27.0 \%)$ & .042 \\
\hline Familial history of SAH & 45 (11.9\%) & $45(11.3 \%)$ & 35 (12.3\%) & $10(8.7 \%)$ & .304 \\
\hline Reason for detection & & & & & \\
\hline $\begin{array}{l}\text { Screening or headache } \\
\text { or dizziness }\end{array}$ & $362(96.0 \%)$ & $383(95.8 \%)$ & $277(97.2 \%)$ & $106(92.2 \%)$ & .002 \\
\hline Symptoms & $5(1.3 \%)$ & $5(1.3 \%)$ & $0(0 \%)$ & $5(4.4 \%)$ & \\
\hline SAH due to another aneurysm & $10(2.7 \%)$ & $12(3.0 \%)$ & $8(2.8 \%)$ & $4(3.5 \%)$ & \\
\hline
\end{tabular}

${ }^{a}$ Results are expressed as mean or no. (\%).

Table 2: Radiologic characteristics of aneurysms

\begin{tabular}{|c|c|c|c|c|}
\hline Characteristic & Total & $\begin{array}{c}\text { Small } \\
(<7 \mathrm{~mm})\end{array}$ & $\begin{array}{c}\text { Large } \\
(\geq 7 \mathrm{~mm})\end{array}$ & $P$ \\
\hline Total no. & 400 & 285 & 115 & \\
\hline \multicolumn{5}{|l|}{$\begin{array}{c}\text { Largest dimension of } \\
\text { aneurysm }\end{array}$} \\
\hline Mean, mm & $6.5 \pm 2.8$ & $5.1 \pm 1.0$ & $10.0 \pm 2.8$ & \\
\hline \multicolumn{5}{|l|}{ Distribution } \\
\hline$<5 \mathrm{~mm}$ & $136(34.0 \%)$ & $136(47.7 \%)$ & & \\
\hline $5-6 \mathrm{~mm}$ & $149(37.3 \%)$ & $149(52.3 \%)$ & & \\
\hline $7-9 \mathrm{~mm}$ & $63(15.8 \%)$ & & $63(54.8 \%)$ & \\
\hline $10-24 \mathrm{~mm}$ & $52(13.0 \%)$ & & $52(45.2 \%)$ & \\
\hline$\geq 25 \mathrm{~mm}$ & $0(0.0 \%)$ & & & \\
\hline Neck size $\geq 4 \mathrm{~mm}$ & $135(33.8 \%)$ & $59(20.7 \%)$ & $76(66.1 \%)$ & $<.001$ \\
\hline \multicolumn{5}{|l|}{ Dome:neck ratio } \\
\hline Mean, mm & $1.7 \pm 0.6$ & $1.6 \pm 0.4$ & $2.2 \pm 0.7$ & $<.001$ \\
\hline$\leq 2$ & $299(74.8 \%)$ & $243(85.3 \%)$ & $56(48.7 \%)$ & $<.001$ \\
\hline Wide neck $1^{\mathrm{a}}$ & $326(81.5 \%)$ & $243(85.3 \%)$ & $83(72.2 \%)$ & .002 \\
\hline \multicolumn{5}{|c|}{ Location of aneurysm } \\
\hline Anterior wall & $97(24.3 \%)$ & $59(20.7 \%)$ & $38(33.0 \%)$ & \\
\hline Ventral paraclinoid & $101(25.3 \%)$ & $70(24.6 \%)$ & $31(27.0 \%)$ & \\
\hline True ophthalmic & $52(13.0 \%)$ & $34(11.9 \%)$ & 18 (15.7\%) & \\
\hline Carotid cave & $150(37.5 \%)$ & $122(42.8 \%)$ & $28(24.3 \%)$ & .003 \\
\hline
\end{tabular}

cation for small aneurysms was the carotid cave (42.8\%), whereas that for large aneurysms was the anterior wall (33.0\%).

\section{Treatment Specifics}

Treatment strategies are summarized in Table 3. All aneurysms were treated by endovascular coil embolization. A stent-assisted technique was more frequently used for large aneurysms $(43.5 \%)$ than for small aneurysms $(17.2 \%)(P<.001)$. The procedures failed for 3 small aneurysms (1.1\%) and 1 large aneurysm $(0.87 \%)$. Among these 4 failures, 2 small aneurysms were retreated on another day by using different strategies. In the other 2 cases, the patients refused retreatment.

\section{Angiographic Outcomes}

Details about the angiographic outcomes are shown in Table 3. Follow-up angiography (DSA or MRA) at 6 months was available for 386 aneurysms (96.5\%). Among them, $273(68.3 \%)$ were examined by DSA. MRA at 2 years (18 \pm 6 months) was available for 291 aneurysms (72.8\%). A total of 37 aneurysms (9.6\%) recurred during the follow-up period, with $81 \%$ of them (30/37) detected by a scheduled angiography at 6 months.

Among the small aneurysms, immediate complete occlusion was achieved for 29 (10.2\%), a neck remnant for 80 (28.1\%), and body filling for 176 (61.8\%). Radiologic follow-up was available for $96.5 \%$ (275/285), with a mean interval of $30 \pm 19$ months (range, 6-96 months). During the follow-up period, the complete occlusion rate increased to $72.4 \%$. Eighteen aneurysms $(6.5 \%)$ recurred, and retreatment was needed for 3 of them (1.1\%).

For the large aneurysms, immediate complete occlusion was achieved in $9(7.8 \%)$, a neck remnant in $40(34.8 \%)$, and body filling in 66 (57.4\%). Radiologic follow-up was available for $96.5 \%(111 / 115)$, with a mean interval of $36 \pm 21$ months (range, 6-83 months). During the follow-up period, complete occlusion was achieved in $55.0 \%$. There were 19 recurrences $(17.1 \%)$, and 7 (6.3\%) underwent retreatment. The distributions of the immediate angiographic outcomes were almost the same in the small and large aneurysm groups $(P=.37)$. During the follow-up period, however, the rate of body filling was significantly higher for large aneurysms than for small aneurysms $(P<.001)$. As a result, the numbers of recurrences and retreatments were significantly higher for large aneurysms $(P=.001$ and $P=.007$, respectively).

The following factors were evaluated as predictors of recurrence: age, sex, location of the aneurysm, side, large ( $\geq 7 \mathrm{~mm})$, wide neck ( $\geq 4 \mathrm{~mm}$ or aspect [dome:neck] ratio of $\leq 2$ ), medical history (hypertension, diabetes mellitus, smoking habit), body filling at initial treatment, use of stent-assisted technique, ischemic complication (Table 4). The univariate analysis indicated that only the large size of an aneurysm was a significant predictor of recurrence $(P=.001)$. In the multivariate analysis, large size was also a significant $(P=.005)$ predictor after correction by side and ischemic complication $(P=.101$ and 0.097 in the univariate analysis, respectively). To show the trend for what we assessed to be major recanalization, the predictors of retreatment were also subjected to univariate analysis (Table 5). Among the factors listed above, large size $(P=.008)$ and former or current smoking habit $(P=.031)$ were associated with retreatment.

\section{Procedure-Related Complications}

There were 16 procedural complications (3.9\%) (Table 6). Thromboembolic complications were most frequent, which occurred in 12 patients $(2.9 \%)$. Among them, permanent morbidity was observed in 3 patients $(0.7 \%)$. Permanent morbidity included in-stent thrombosis that resulted in ICA occlusion in 1 patient and visual impairment due to an embolism in the ophthalmic 
Table 3: Treatment strategies and results

\begin{tabular}{lcccc}
\hline & Total & $<7 \mathrm{~mm}$ & $\geq 7 \mathrm{~mm}$ & $\boldsymbol{P}$ \\
\hline No. treated aneurysms & 400 & 285 & 115 & \\
Strategy & & & & \\
$\quad$ Stent-assisted & $99(24.8 \%)$ & $49(17.2 \%)$ & $50(43.5 \%)$ & $<.001$ \\
$\quad$ Not stent-assisted & $301(75.3 \%)$ & $236(82.8 \%)$ & $65(56.5 \%)$ & \\
$\quad$ Simple technique & $20(5.0 \%)$ & $14(4.9 \%)$ & $6(5.2 \%)$ & \\
$\quad$ Balloon-assisted & $277(69.3 \%)$ & $219(76.8 \%)$ & $58(50.4 \%)$ & \\
$\quad$ Failed & $4(1.0 \%)$ & $3(1.1 \%)$ & $1(0.87 \%)$ & \\
Immediate angiographic outcome & & & & \\
$\quad$ Complete occlusion & $38(9.5 \%)$ & $29(10.2 \%)$ & $9(7.8 \%)$ & .374 \\
$\quad$ Neck remnant & $120(30.0 \%)$ & $80(28.1 \%)$ & $40(34.8 \%)$ & \\
$\quad$ Body filling & $242(60.5 \%)$ & $176(61.8 \%)$ & $66(57.4 \%)$ & \\
Follow-up angiographic outcome ${ }^{\mathrm{a}}$ & & & & \\
$\quad$ Complete occlusion & $260(67.4 \%)$ & $199(72.4 \%)$ & $61(55.0 \%)$ & $<.001$ \\
$\quad$ Neck remnant & $81(21.0 \%)$ & $60(21.8 \%)$ & $21(18.9 \%)$ & \\
$\quad$ Body filling & $45(11.7 \%)$ & $16(5.8 \%)$ & $29(26.1 \%)$ & \\
Recurrence & $37(9.6 \%)$ & $18(6.5 \%)$ & $19(17.1 \%)$ & .001 \\
$\quad$ Conservative treatment & $27(7.0 \%)$ & $15(5.4 \%)$ & $12(10.8 \%)$ & .059 \\
$\quad$ Retreatment & $10(2.6 \%)$ & $3(1.1 \%)$ & $7(6.3 \%)$ & .007 \\
Rupture during follow-up ${ }^{\mathrm{a}}$ & $1(0.3 \%)$ & 0 & $1(0.9 \%)$ & .286 \\
\hline a Follow-up data of 386 patients. & & & &
\end{tabular}

Table 4: Predictors of recurrence ${ }^{a}$

\begin{tabular}{|c|c|c|c|c|c|}
\hline \multirow[b]{2}{*}{ Predictor } & \multirow[b]{2}{*}{ Recurrent } & \multirow{2}{*}{$\begin{array}{c}\text { Not } \\
\text { Recurrent }\end{array}$} & \multirow{2}{*}{$\begin{array}{c}\begin{array}{c}\text { Univariate } \\
\text { Analysis }\end{array} \\
P\end{array}$} & \multicolumn{2}{|c|}{ Multivariate Analysis } \\
\hline & & & & $P$ & OR $(95 \% \mathrm{Cl})$ \\
\hline No. treated aneurysms & 37 & 349 & & & \\
\hline Mean age, $y$ & $56.4 \pm 11.6$ & $56.9 \pm 11.2$ & .784 & & \\
\hline Men & $6(16.2 \%)$ & 39 (11.2\%) & .415 & & \\
\hline Location & & & .733 & & \\
\hline Anterior wall & $8(21.6 \%)$ & $87(24.9 \%)$ & & & \\
\hline Ventral paraclinoid & $12(32.4 \%)$ & $84(24.1 \%)$ & & & \\
\hline True ophthalmic & $4(10.8 \%)$ & 45 (12.9\%) & & & \\
\hline Carotid cave & $13(35.1 \%)$ & $133(38.1 \%)$ & & & \\
\hline Right side & $21(56.8 \%)$ & $149(42.7 \%)$ & .101 & .114 & $1.75(0.88-3.6)$ \\
\hline Size $\geq 7 \mathrm{~mm}$ & $19(51.4 \%)$ & $92(26.4 \%)$ & .001 & .005 & $2.75(1.36-5.58)$ \\
\hline Wide neck ${ }^{\mathrm{b}}$ & $30(81.1 \%)$ & $284(81.4 \%)$ & .965 & & \\
\hline \multicolumn{6}{|l|}{ Medical history } \\
\hline Hypertension & $19(51.4 \%)$ & $137(39.3 \%)$ & .154 & & \\
\hline Diabetes mellitus & $3(8.1 \%)$ & $15(4.3 \%)$ & .399 & & \\
\hline Former or current smoker & $10(27.0 \%)$ & $67(19.2 \%)$ & .257 & & \\
\hline Body filling at initial treatment & $21(58.3 \%)$ & $213(61.2 \%)$ & .737 & & \\
\hline Not stent-assisted & 29 (78.4\%) & $261(74.8 \%)$ & .631 & & \\
\hline Ischemic complication & $3(8.1 \%)$ & $9(2.6 \%)$ & .097 & .264 & $2.35(0.48-8.83)$ \\
\hline
\end{tabular}

${ }^{a}$ Results are given as the mean or no. (\%).

${ }^{b}$ Neck of $\geq 4 \mathrm{~mm}$ or aspect (dome:neck) ratio $\leq 2$.

artery in 2 patients. In the other 9 patients (2.2\%), the symptoms were mild and resolved spontaneously within a few days. Thromboembolic complications were found significantly more often in patients with large aneurysms (9/122) than in those with small ones $(3 / 290)(P=.001)$.

Hemorrhagic complications (intraprocedural aneurysm rupture) occurred in 2 patients $(0.5 \%)$, both with small aneurysms. One of them $(0.2 \%)$ resulted in permanent morbidity. Other complications were observed in 2 patients $(0.5 \%)$. Visual disturbance and oculomotor nerve palsy due to compression by coil mass occurred in 1 patient each $(0.2 \%)$. Neither resulted in permanent morbidity. Complications associated with the coil mass were seen only in large aneurysms. Overall, permanent morbidity rates were $1.0 \%$ for small aneurysms and $0.8 \%$ for large ones $(P=1.0)$.

\section{Long-Term Clinical Outcome}

In the small-aneurysm group, among 273 patients with 285 aneurysms, clinical follow-up was available for 268 patients. The mean clinical follow-up duration was $32 \pm 19$ months (range, 6-97 months). Poor clinical outcomes were observed in 2 patients $(0.7 \%)$, both of which were procedure-related ( $\mathrm{mRS}=3$ in both cases).

Among 113 patients with 115 large aneurysms, clinical follow-up was available for 112 patients. The mean clinical follow-up duration was $39 \pm 21$ months (range, 6-88 months). Poor clinical outcomes were observed in 3 patients $(2.7 \%)$. All were unrelated to the procedure and included cerebral infarction ( $\mathrm{mRS}=4$ ), cerebral hemorrhage $(\mathrm{mRS}=4)$, and pontine hemorrhage $(\mathrm{mRS}=6)$. One patient with a large aneurysm $(9.0 \mathrm{~mm})$ had aneurysmal rupture owing to recanalization 2 months after treatment, but the patient had a good clinical outcome after additional endovascular treatment $(\mathrm{mRS}=0)$.

\section{DISCUSSION}

Unruptured intracranial aneurysms are common and occurred in approximately $1 \%-2 \%$ of the population, as reviewed by Vlak et al. ${ }^{19}$ Because most unruptured intracranial aneurysms are asymptomatic and are found incidentally, treatment should be considered after balancing the natural history of the aneurysm with the risk posed by the treatment. Prospective data for the natural history of unruptured intracranial aneurysms by the International Study of Unruptured Intracranial Aneurysms and UCAS Japan investigators showed that the annual rupture rate increased for aneurysms that were $\geq 7$ $\mathrm{mm}$. The presence of a daughter sac and a history of SAH increased the rupture rate. ${ }^{5,7}$ In the Japanese cohort, the annual rupture rates for paraclinoid aneurysms were approximately $0.1 \%, 1 \%$, and $10 \%$ when they were $<7 \mathrm{~mm}, 7-24 \mathrm{~mm}$, and $>25$ $\mathrm{mm}$, respectively, in size. ${ }^{7}$ Analysis of our data showed that the 6-month morbidity and mortality rates for aneurysms $\geq 7 \mathrm{~mm}$ were acceptably low ( $0.8 \%$ and $0 \%$, respectively). The retreatment rate with a mean follow-up interval of 39 months was also acceptable (6.3\%). Prophylactic treatment of these unruptured aneurysms could be rationalized. The indications for endovascular treatment of small paraclinoid aneurysms, however, should be carefully assessed on an individual basis after considering the patient and aneurysmal factors, such as medical comorbidities, patient age, a history of SAH, the presence of a daughter sac, 
Table 5: Predictors of the need for retreatment ${ }^{a}$

\begin{tabular}{lccc} 
& & No & $\begin{array}{c}\text { Univariate } \\
\text { Analysis }\end{array}$ \\
\cline { 3 - 4 } \multicolumn{1}{c}{ Parameter } & Retreatment & Retreatment & $\boldsymbol{P}$ \\
\hline No. re-treated aneurysms & 10 & 376 & \\
Mean age, $y$ & $57.6 \pm 9.5$ & $56.8 \pm 11.2$ & .826 \\
Men & $3(30.0 \%)$ & $42(11.2 \%)$ & .099 \\
Location & & & .156 \\
$\quad$ Anterior wall & $2(20.0 \%)$ & $93(24.7 \%)$ & \\
Ventral paraclinoid & $5(50.0 \%)$ & $91(24.2 \%)$ & \\
True ophthalmic & $2(20.0 \%)$ & $47(12.5 \%)$ & \\
Carotid cave & $1(10.0 \%)$ & $145(38.6 \%)$ & .755 \\
$\quad$ Right side & $5(50.0 \%)$ & $165(43.9 \%)$ & .008 \\
Size $\geq 7$ mm & $7(70.0 \%)$ & $104(27.7 \%)$ & 1 \\
Wide neck & $2(20.0 \%)$ & $70(18.6 \%)$ & \\
Medical history & & & .212 \\
$\quad$ Hypertension & $6(60.0 \%)$ & $150(39.9 \%)$ & .074 \\
Diabetes mellitus & $2(20.0 \%)$ & $16(4.3 \%)$ & .031 \\
Former or current smoker & $5(50.0 \%)$ & $72(19.2 \%)$ & .521 \\
Body filling at initial treatment & $5(50.0 \%)$ & $229(61.2 \%)$ & 1 \\
Not stent-assisted & $2(20.0 \%)$ & $94(25.0 \%)$ & .274 \\
Ischemic complication & $1(10.0 \%)$ & $11(2.9 \%)$ & \\
\hline Results are expressed as the & & & \\
\hline
\end{tabular}

${ }^{a}$ Results are expressed as the mean or no. (\%).

${ }^{\mathrm{b}}$ Neck of $\geq 4 \mathrm{~mm}$ or aspect (dome:neck) ratio $\leq 2$.

\section{Table 6: Complications}

\begin{tabular}{lcccc}
\hline & Total & $<7 \mathrm{~mm}$ & $\geq 7 \mathrm{~mm}$ & $\boldsymbol{P}$ \\
\hline No. procedures & 412 & 290 & 122 & \\
Total complications & $16(3.9 \%)$ & $5(1.7 \%)$ & $11(9.0 \%)$ & .001 \\
$\quad$ Transient & $12(2.9 \%)$ & $2(0.7 \%)$ & $10(8.2 \%)$ & $<.001$ \\
$\quad$ Permanent & $4(1.0 \%)$ & $3(1.0 \%)$ & $1(0.8 \%)$ & 1 \\
Details & & & & \\
$\quad$ Ischemic complications & & & & \\
$\quad$ Total & $12(2.9 \%)$ & $3(1.0 \%)$ & $9(7.4 \%)$ & .001 \\
$\quad$ Transient & $9(2.2 \%)$ & $1(0.3 \%)$ & $8(6.6 \%)$ & $<.001$ \\
$\quad$ Permanent & $3(0.7 \%)$ & $2(0.7 \%)$ & $1(0.8 \%)$ & 1 \\
Hemorrhagic complications & & & & \\
$\quad$ Total & $2(0.5 \%)$ & $2(0.7 \%)$ & 0 & 1 \\
$\quad$ Transient & $1(0.2 \%)$ & $1(0.3 \%)$ & 0 & 1 \\
$\quad$ Permanent & $1(0.2 \%)$ & $1(0.3 \%)$ & 0 & 1 \\
Others & \multicolumn{4}{c}{0} \\
$\quad$ Total & $2(0.5 \%)$ & 0 & $2(1.6 \%)$ & .087 \\
$\quad$ Transient & $2(0.5 \%)$ & 0 & $2(1.6 \%)$ & .087 \\
$\quad$ Permanent & 0 & 0 & 0 & 1 \\
\hline
\end{tabular}

aneurysmal size, and aneurysmal enlargement. Treatment may be considered when patients are predicted to be at relatively high risk of rupture because the 6-month morbidity and retreatment rates for small aneurysms are low $(1.0 \%$ and $1.1 \%$, respectively).

Unruptured paraclinoid aneurysms have been increasingly treated endovascularly for anatomic reasons. ${ }^{9-15,20}$ Colli et $\mathrm{al}^{2}$ reviewed microsurgical outcomes of paraclinoid aneurysms, which showed that total complication rates were $21.3 \%-41.7 \%$. The complications included intraoperative aneurysm rupture in $0.8 \%-14.3 \%$, occlusion of the ICA in $1.2 \%-13.6 \%$, and visual impairment in $1.8 \%-33.3 \% .^{2}$ Mortality rates associated with microsurgical treatment in unruptured cases were $0 \%-10.0 \%{ }^{2}$ Total neurologic complications associated with endovascular coil embolization of unruptured paraclinoid aneurysms reported after 2010, including this study, were $1.4 \%-6.7 \%$ and mortality was $0 \%,{ }^{10-12,14,15,21}$ which demonstrated that endovascular treatment was more appropriate for prophylactic treatment of these aneurysms. Paraclinoid aneurysms are increasingly being treated with flow-diversion stents, which may further reduce the procedural risks associated with endovascular treatment. ${ }^{22-25}$
Angiographic and clinical outcomes from previous studies are summarized in Table 7. The immediate complete occlusion rate in our series was low $(9.5 \%)$ compared with those in earlier studies $(28.2 \%-86.6 \%) .^{9-15,21}$ The complete occlusion rate in the late stage, however, reached approximately $70 \%$, which was similar to those reported in previous studies $(54.0 \%-87.8 \%) .^{9-15,21}$ The results indicated that aggressive coil packing was not essential for good angiographic outcomes during the late stage because of the possibility of subsequent thrombus formation around the coil mass.

The recurrence rate in this region differed among studies, which ranged from $5.0 \%$ to $23.1 \% .^{9-15,21}$ D'Urso et al ${ }^{15}$ reported that stent-assisted coil embolization was associated with a lower recurrence rate than that seen with a simple technique $(6 \%$ vs $19 \%, P=.171)$. Their results were replicated by Yadla et $\mathrm{al}^{21}$ (9.4\% vs $24.6 \%, P=.03$ ). In our series, however, stent use did not affect the recurrence rate $(8.3 \%$ vs $10.0 \%, P=.63)$. This could be due to different indications for using the stent-assisted technique among studies. The proportion of stent-assisted embolization was higher in our series, which indicated that the total recurrence rate could be reduced if the stent-assisted technique were properly applied for likely-to-recur aneurysms in this region.

We showed that the mean interval from the initial treatment to recurrence was $7.8 \pm 5.0$ months, and recurrence was rarely detected after the first posttreatment year (Figure). Consistent with our results, Wang et $\mathrm{al}^{10}$ reported that recurrence was detected in $12.5 \%$ of cases at a mean interval of $9.89 \pm 5.21$ months. Although Yadla et $\mathrm{al}^{21}$ showed that recurrence was detected in $17.8 \%$ of cases, at a mean interval of 28.3 months, the difference might be caused by the scheduled timing of follow-up angiography. Follow-up angiography at 6-12 months would be reasonable for detecting late recanalization. Aneurysm rupture after recanalization has been rare, with only 3 cases reported to date, including 1 case in this study (Table 7). Still, it is of note that the rupture occurred as early as 2 months after coil embolization in these cases. Thus, additional follow-up MRA at 1 month may be needed to detect acute recanalization that could cause aneurysmal rupture.

Previous studies showed that the size of the aneurysms was associated with the recurrence rate, ${ }^{10,12,15}$ and analysis of our data indicated that aneurysms of $\geq 7 \mathrm{~mm}$ were at a higher risk of recurrence. Previous reports, however, did not analyze the relationship between aneurysm size and the type of complications. Analysis of our data indicated that large aneurysms were likely to be associated with ischemic complications and that small aneurysms were associated with hemorrhagic complications. This finding was consistent with previously published data by Shigematsu et al. ${ }^{26}$

There were several limitations to our study. First, the study was designed as a retrospective review based on a single-center experience. Therefore, it might not be suitable to compare the data with those of a prospective cohort study (UCAS Japan). However, because of the relatively high risk of rupture for large aneurysms in this region, it is not reasonable to conduct a prospective controlled trial. Cost-effective analysis may provide further support for the rationale of prophylactic treatment for unruptured aneurysms.

AJNR Am J Neuroradiol 37:679-85 Apr 2016 www.ajnr.org 


\begin{tabular}{|c|c|c|c|c|c|c|c|c|c|}
\hline Study, y & $\begin{array}{c}\text { No. } \\
\text { Aneurysms }\end{array}$ & $\begin{array}{c}\text { Immediate } \\
\text { CO, } \%\end{array}$ & $\begin{array}{c}\text { Follow-Up } \\
\text { CO, \% }\end{array}$ & $\begin{array}{c}\text { Early Follow-Up } \\
\text { Angiography }\end{array}$ & $\begin{array}{c}\text { Angiographic } \\
\text { Follow-Up, } \\
\text { mo }\end{array}$ & $\begin{array}{l}\text { Recurrence } \\
\text { Rate, \% }\end{array}$ & $\begin{array}{c}\text { Time to } \\
\text { Recurrence, } \\
\text { mo }\end{array}$ & $\begin{array}{c}\text { No. } \\
\text { Rupture } \\
\text { (mo after } \\
\text { EVT) }\end{array}$ & $\begin{array}{c}\text { Morbidity } \\
\text { Rate, \% }\end{array}$ \\
\hline Present series & 400 & 9.5 & 67.4 & DSA at $6 \mathrm{mo}$ & $32 \pm 20$ & 9.5 & $7.8 \pm 5.0$ & $1(2)$ & 1 \\
\hline Wang et al, $2013^{10}$ & 142 & 43.7 & 63.4 & $\mathrm{DSA}<12 \mathrm{mo}$ & $13.41 \pm 2.64$ & 12.5 & $9.89 \pm 5.21$ & $1(2)$ & 0 \\
\hline D'Urso et al, $2012^{15}$ & 126 & 38 & 62 & MRA or DSA & $31.9 \pm 28.4$ & 17 & - & 0 & 0.8 \\
\hline Sorimachi et al, $2012^{12}$ & 140 & 33.6 & 55 & DSA at $6 \mathrm{mo}$ & $65.6 \pm 37.2$ & 11.1 & - & 0 & 0.7 \\
\hline Yadla et al, $2011^{21}$ & 147 & 68.6 & 64.1 & MRA at 6-12 mo & - & 17.8 & 28.3 & 0 & 1.4 \\
\hline Sun et al, $2011^{11}$ & 30 & 86.6 & 81.5 & DSA at 3-18 mo & 7.8 & 7.4 & - & 0 & 3.3 \\
\hline Kwon et al, $2010^{14}$ & 132 & 58 & - & MRA at 6 mo & 6 & 5 & - & 0 & 0 \\
\hline Park et al, $2003^{13}$ & 73 & 72.6 & 87.8 & Angiography at $6 \mathrm{mo}$ & 13.9 & 23.1 & - & 0 & 8.3 \\
\hline Thornton et al, $2000^{9}$ & 71 & 28.2 & 54 & Angiography at $6 \mathrm{mo}$ & 16 & 16.4 & - & $1(2)$ & 5.6 \\
\hline
\end{tabular}

Note:-CO indicates complete occlusion; EVT, endovascular treatment; -, not available.

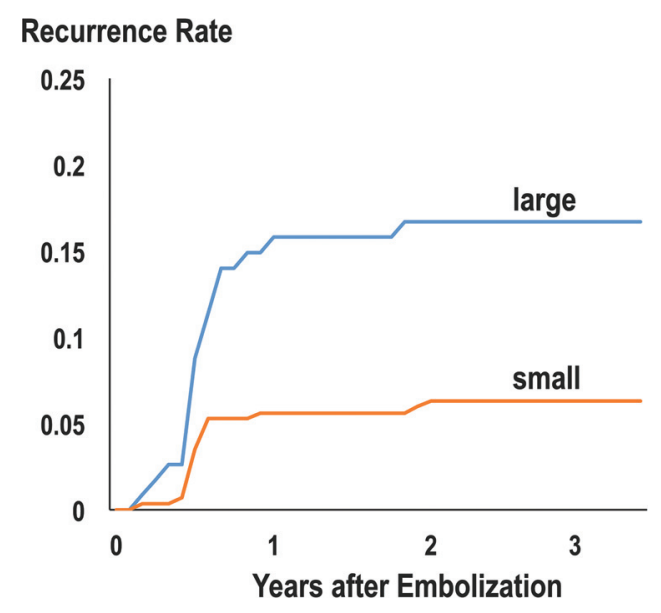

FIGURE. Recurrence rates after the initial treatment according to the size of the aneurysms. Most recurrences were detected within 1 year after treatment.

Second, indications for endovascular treatment of small aneurysms were addressed in an individualized fashion according to the patient age, history of SAH, family history of $\mathrm{SAH}$, size, shape (ie, the presence of a daughter sac) and multiplicity of the aneurysm, aneurysmal enlargement, patient anxiety and mental status, and comorbidities (eg, hypertension). Many of these parameters can be associated with an increased risk of rupture for small aneurysms. ${ }^{27}$ However, such parameters were not precisely provided, and we could not determine whether the decision-making process was consistent. Indications might have been altered after publication of data from large cohorts, such as in the Small Unruptured Intracranial Aneurysm Verification Study or UCAS Japan. ${ }^{7,27}$ This was also a limitation that stems from the retrospective nature of our study.

Third, platelet function testing was not performed in this study population, though there is evidence that the hyporesponse to clopidogrel is associated with increased risk of thromboembolic complications. ${ }^{28-31}$ Selection of the antiplatelet drugs might have influenced the increased incidence of thromboembolic events in large aneurysms that were treated by using the stentassisted technique.

\section{CONCLUSIONS}

Endovascular treatment of unruptured paraclinoid aneurysms $\geq 7 \mathrm{~mm}$ can be achieved with high technical success, low complication rates, and excellent long-term outcomes. Treatment of unruptured paraclinoid aneurysms $<7 \mathrm{~mm}$ may be considered in patients, based on an individualized assessment of risk factors, including medical comorbidities, patient age, ethnicities, aneurysm characteristics, and history of SAH.

Disclosures: Nobuyuki Sakai-UNRELATED: Grants/Grants Pending: Terumo (modest)*; Payment for Lectures (including service on speakers bureaus): Codman, Covidien, Stryker, Terumo, Comments: Modest. *Money paid to the institution.

\section{REFERENCES}

1. Kim JM, Romano A, Sanan A, et al. Microsurgical anatomic features and nomenclature of the paraclinoid region. Neurosurgery 2000;46: 670-80; discussion 680-82 Medline

2. Colli BO, Carlotti CG, Assirati JA, et al. Results of microsurgical treatment of paraclinoid carotid aneurysms. Neurosurg Rev 2013; 361:99-114; discussion 114-15 CrossRef Medline

3. Lee EJ, Lee HJ, Hyun MK, et al. Rupture rate for patients with untreated unruptured intracranial aneurysms in South Korea during 2006-2009. J Neurosurg 2012;117:53-59 CrossRef Medline

4. Juvela S, Porras M, Poussa K. Natural history of unruptured intracranial aneurysms: probability of and risk factors for aneurysm rupture. J Neurosurg 2000;93:379-87 Medline

5. Unruptured intracranial aneurysms-risk of rupture and risks of surgical intervention. International Study of Unruptured Intracranial Aneurysms Investigators. $N$ Engl J Med 1998:339:1725-33 CrossRef Medline

6. Juvela S, Poussa K, Lehto H, et al. Natural history of unruptured intracranial aneurysms: a long-term follow-up study. Stroke 2013; 44:2414-21 CrossRef Medline

7. UCAS Japan Investigators, Morita A, Kirino $\mathrm{T}$, et al. The natural course of unruptured cerebral aneurysms in a Japanese cohort. N Engl J Med 2012;366:2474-82 CrossRef Medline

8. Wiebers DO, Whisnant JP, Huston J, et al. Unruptured intracranial aneurysms: natural history, clinical outcome, and risks of surgical and endovascular treatment. Lancet 2003:362:103-10 CrossRef Medline

9. Thornton J, Aletich VA, Debrun GM, et al. Endovascular treatment of paraclinoid aneurysms. Surg Neurol 2000;54:288-99 CrossRef Medline

10. Wang Y, Li Y, Jiang C, et al. Endovascular treatment of paraclinoid aneurysms: 142 aneurysms in one centre. J Neurointerv Surg 2013;5: 552-56 CrossRef Medline

11. Sun Y, Li Y, Li A. Endovascular treatment of paraclinoid aneurysms. Interv Neuroradiol 2011;17:425-30 Medline

12. Sorimachi T, Ito $\mathrm{Y}$, Morita $\mathrm{K}$, et al. Long-term follow-up of intraaneurysmal coil embolization for unruptured paraclinoid aneurysms. Neurol Res 2012;34:864-70 CrossRef Medline

13. Park HK, Horowitz M, Jungreis C, et al. Endovascular treatment of paraclinoid aneurysms: experience with 73 patients. Neurosurgery 2003;53:14-23; discussion 24 CrossRef Medline

14. Kwon BJ, Im S-H, Park JC, et al. Shaping and navigating methods of microcatheters for endovascular treatment of paraclinoid aneurysms. Neurosurgery 2010;67:34-40 CrossRef Medline 
15. D’Urso PI, Karadeli HH, Kallmes DF, et al. Coiling for paraclinoid aneurysms: time to make way for flow diverters? AJNR Am J Neuroradiol 2012;33:1470-74 CrossRef Medline

16. al-Rodhan NR, Piepgras DG, Sundt TM. Transitional cavernous aneurysms of the internal carotid artery. Neurosurgery 1993;33:99396; discussion 997-98 CrossRef Medline

17. Iihara K, Murao K, Sakai $\mathrm{N}$, et al. Unruptured paraclinoid aneurysms: a management strategy. J Neurosurg 2003;99:241-47 CrossRef Medline

18. Ng P, Khangure MS, Phatouros CC, et al. Endovascular treatment of intracranial aneurysms with Guglielmi detachable coils: analysis of midterm angiographic and clinical outcomes. Stroke 2002;33: 210-17 CrossRef Medline

19. Vlak MH, Algra A, Brandenburg R, et al. Prevalence of unruptured intracranial aneurysms, with emphasis on sex, age, comorbidity, country, and time period: a systematic review and meta-analysis. Lancet Neurol 2011;10:626-36 CrossRef Medline

20. Ferrell AS, Lessne ML, Alexander MJ, et al. Visual complications after stent-assisted endovascular embolization of paraophthalmic and suprasellar variant superior hypophyseal aneurysms: the Duke Cerebrovascular Center experience in $\mathbf{5 7}$ patients. World Neurosurg 2012:78:289-94 CrossRef Medline

21. Yadla S, Campbell PG, Grobelny B, et al. Open and endovascular treatment of unruptured carotid-ophthalmic aneurysms: clinical and radiographic outcomes. Neurosurgery 2011;68:1434-43; discussion 1443 CrossRef Medline

22. Fang S, Lanzino G. Paraclinoid aneurysms: is there a new endovascular standard? Neurol Res 2014;36:314-22 CrossRef Medline

23. Kim LJ, Tariq F, Levitt M, et al. Multimodality treatment of complex unruptured cavernous and paraclinoid aneurysms. Neurosurgery 2014;74:51-61; discussion 61; quiz 61 CrossRef Medline

24. Lanzino G, Crobeddu E, Cloft HJ, et al. Efficacy and safety of flow diversion for paraclinoid aneurysms: a matched-pair analysis compared with standard endovascular approaches. AJNR Am J Neuroradiol 2012;33:2158-61 CrossRef Medline

25. Loumiotis I, D'Urso PI, Tawk R, et al. Endovascular treatment of ruptured paraclinoid aneurysms: results, complications, and follow-up. AJNR Am J Neuroradiol 2012;33:632-37 CrossRef Medline

26. Shigematsu T, Fujinaka T, Yoshimine T, et al. Endovascular therapy for asymptomatic unruptured intracranial aneurysms: JR-NET and JR-NET2 findings. Stroke 2013;44:2735-42 CrossRef Medline

27. Sonobe M, Yamazaki T, Yonekura M, et al. Small unruptured intracranial aneurysm verification study: SUAVe study, Japan. Stroke 2010;41:1969-77 CrossRef Medline

28. Delgado Almandoz JE, Crandall BM, Scholz JM, et al. Pre-procedure P2Y12 reaction units value predicts perioperative thromboembolic and hemorrhagic complications in patients with cerebral aneurysms treated with the Pipeline embolization device. J Neurointerv Surg 2013;5(suppl 3):iii3-10 CrossRef Medline

29. Delgado Almandoz JE, Kadkhodayan Y, Crandall BM, et al. Variability in initial response to standard clopidogrel therapy, delayed conversion to clopidogrel hyper-response, and associated thromboembolic and hemorrhagic complications in patients undergoing endovascular treatment of unruptured cerebral aneurysms. J Neurointerv Surg 2014;6:767-73 CrossRef Medline

30. Lee DH, Kim HS, Kim SM, et al. Change of platelet reactivity to antiplatelet therapy after stenting procedure for cerebral artery stenosis: VerifyNow antiplatelet assay before and after stenting. Neurointervention 2012;7:23-6 CrossRef Medline

31. Kang H-S, Kwon BJ, Kim JE, et al. Preinterventional clopidogrel response variability for coil embolization of intracranial aneurysms: clinical implications. AJNR Am J Neuroradiol 2010;31: 1206-10 CrossRef Medline 